Preprints of the

Max Planck Institute for

Research on Collective Goods

Bonn 2009/4

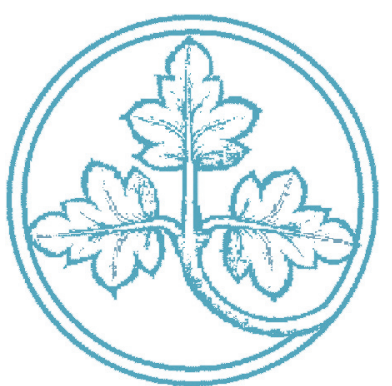

Deterrence Through

Word of Mouth

Johannes Rincke / Christian Traxler

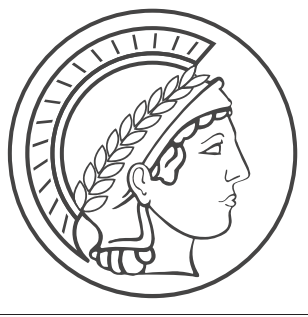

MAX PLANCK SOCIETY 


\title{
Deterrence Through Word of Mouth
}

\author{
Johannes Rincke / Christian Traxler
}

January 2009

Max Planck Institute for Research on Collective Goods, Kurt-Schumacher-Str. 10, D-53113 Bonn http://www.coll.mpg.de 


\title{
Deterrence Through Word of Mouth*
}

\author{
Johannes Rincke ${ }^{\S}$ and Christian Traxler**
}

January 2009

\begin{abstract}
The deterrent effect of law enforcement rests on the link between the actual and the perceived detection risk. We study the role of word of mouth for this linkage. Our approach makes use of micro data on compliance with TV license fees allowing us to distinguish between households who have been subject to enforcement and those who have not. Exploiting local variation in field inspectors' efforts induced by snowfall, we find a striking response of households to increased enforcement in their vicinity, with compliance rising significantly among those who had no interaction with inspectors. As we can exclude other channels of information transmission, our finding establishes a substantial deterrent effect mediated by word of mouth.
\end{abstract}

JEL classification: K42, D83

Keywords: Deterrence; Law enforcement; Word of mouth

${ }^{*}$ We would like to thank Johannes Binnswanger, Christoph Engel, Dennis Epple, Martin Halla, Florian Heiss, Martin Hellwig, Michael Kurschilgen, Lars Lefgren, Fabrice Le-Lec, Friederike Mengel, Naci Mocan, Holger Sieg, Victor Steiner, Philipp Weinschenk and Joachim Winter for helpful comments and suggestions. The paper also benefited from discussions at seminars in Berlin (FU), Bonn (IZA, MPI), Innsbruck, Mannheim and Munich. The invaluable support of Annette Chemnitz, Herbert Denk and Gabriela Jerome (FIS), Christian Brandstätter (KfV), Zoltán Daróczi (WIGeoGIS) and the Institute for Meteorology and Geodynamics, Vienna, as well as the financial support by the Austrian National Bank (OeNB Jubiläumsfonds, Grant No. 12301) and the German Research Foundation (DFG) is gratefully acknowledged. Johannes Rincke would like to thank the Carnegie Mellon University for its hospitality. Carina Woodage and Marcus Strobel provided excellent research assistance. Any remaining errors are our own.

$\S$ University of Munich, Department of Economics, Seminar for Economic Policy, johannes.rincke@lrz.uni-muenchen.de

${ }^{* *}$ Corresponding Author. Max Planck Institute for Research on Collective Goods, Bonn, traxler@coll.mpg.de 


\section{Introduction}

Over the last decade, a growing number of studies have provided evidence supporting Becker's (1968) model of crime. While several contributions have identified a deterrent impact of sanctions (Kessler and Levitt, 1999; Drago et al., 2007) and a negative effect of police on crime (Corman and Mocan, 2000; Levitt, 2002; Di Tella and Schargrodsky, 2004), the channels through which deterrence is actually achieved are less clear. In particular, we know little about the mechanisms through which an increase in enforcement will ultimately affect the behavior of individuals.

Evidently, the link between the actual level of law enforcement and the corresponding perceptions of individuals is of key importance for enforcement policies to become effective. Relaxing Becker's assumption that the detection probability is common knowledge, Sah (1991) has analyzed the evolution of individual risk perceptions and the corresponding coevolution of crime. In his model, the agents update their perceived detection risk based on information obtained from sampling in their vicinity. This updating establishes a positive linkage between enforcement and compliance. Although empirical studies have shown that individual beliefs about the detection risk are indeed responsive to personal experience with the criminal justice system (Lochner, 2007), ${ }^{1}$ there is still no evidence on the responsiveness of compliance behavior to information obtained from sampling. This dearth of evidence on the policy-to-perception and perception-to-behavior link is considered as one of the major gaps in deterrence research (Nagin, 1998).

The present paper provides results which contribute to closing this gap. More precisely, our aim is to distinguish empirically between a direct and an indirect deterrent effect of enforcement. While the direct effect works through the updating of risk perceptions based on personal experience, the indirect effect is driven by 'word of mouth', i.e. an updating based on sampling among acquaintances. To disentangle these effects, we exploit micro

\footnotetext{
${ }^{1}$ Earlier contributions include Richards and Tittle (1982), Horney and Marshall (1992), Parker and Grasmick (1979), Paternoster et al. (1985), and Piliavin et al. (1986). Further evidence is discussed in Nagin (1998).
} 
data on the enforcement of TV licence fees and households' compliance behavior. In this setting, enforcement is not publicly observable and targeted to individual households. This distinctive feature enables us to distinguish between households who have been subject to enforcement and those who have not. The empirical investigation then tracks the response of 'untreated' households to the level of enforcement targeted at other households in their vicinity. We find striking evidence of a strong behavioral response to increased enforcement. Since our setting allows us to exclude other channels of information transmission, we conclude that the change in behavior of untreated households must be driven by treated households communicating their experience within their circle of acquaintances. Hence, our empirical findings establish an indirect deterrent effect of enforcement which is mediated by word of mouth.

Our analysis builds on unique data on the Austrian TV licence fee system. There are several reasons which render this institution ideal for the purpose of our study. Firstly, the enforcement of the fees involves licensing inspectors approaching individual households, providing us with an unambiguous measure of detected violations of the law. Secondly, the activity of the inspectors is not observable to the public: their presence in a community is not announced, they are non-uniformed and they do not use any police-like cars. Hence, there remain two ways in which households can learn about the local level of enforcement personal experience and word of mouth. Thirdly, we benefit from using households' unsolicited registrations for the payment of licence fees as a measure for the behavioral response to enforcement. Focusing on quit decisions, i.e. the decision of households who deviate from the law and stop doing so, is a novel approach in empirical studies of deterrence. ${ }^{2}$ Apart from allowing us to avoid typical problems associated with the measurement of crime rates (see Levitt, 1998; MacDonald, 2002), the use of quit decisions assures that there is no scope for crime displacement - in particular, the relocation of law violations in response to increased local enforcement - to drive our results (Jacob et al., 2007).

Based on a record of household-level data on all unsolicited registrations for TV licence

\footnotetext{
${ }^{2}$ As we will discuss below, these decisions can be understood as an implicit form of self-reporting as studied in Kaplow and Shavell (1994).
} 
fees and enforcement by inspectors for the period from November 2005 to March 2006, we construct a panel of monthly enforcement and registration rates. The rates are aggregated at the level of municipalities with a median size of 900 households. We then estimate the impact of enforcement on unsolicited registrations. To avoid problems related to the likely endogeneity of inspectors' enforcement activities, we follow an instrumental variables strategy. We use descriptors of local weather and driving conditions - snowfall and the frequency of car accidents - as instrumental variables. ${ }^{3}$ These instruments are motivated by a number of facts: first of all, licensing inspectors work under piece-rate contracts without being reimbursed for the time spent on traveling, and they independently choose when and where to become active. Furthermore, the time period under consideration was characterized by record breaking levels of snowfall. Hence, for licensing inspectors, the decision where to go became an important one in terms of the opportunity costs of traveling. Finally, Austria is an alpine country with strong regional variation in terms of accessibility during periods of heavy snowfall, providing most inspectors with an option to trim their traveling plans towards areas with reasonable driving conditions. It turns out that our instruments are strong predictors for actual enforcement levels. As conjectured, inspectors respond to their piece-rate incentives, avoiding regions which are more difficult to access in the presence of poor driving conditions.

Exploiting the exogenous variation in enforcement induced by our instruments, we find that an increase in enforcement has a significant impact on unsolicited registrations: on average, three detections by licensing inspectors trigger one additional unsolicited registration. Given that the scope for the indirect deterrence effect is limited by a high overall compliance level, the estimated effect is sizable. We analyze the sensitivity of this result with respect to cases which could potentially be driven by direct exposure to enforcement. All our additional estimations confirm that the observed deterrence effect is driven by the dispersion of information on enforcement through word of mouth.

The remainder of the paper is organized as follows. We first describe the institutional

\footnotetext{
${ }^{3}$ Using weather conditions as instrumental variables relates our approach to Miguel et al. (2004) and Jacob et al. (2007).
} 
background. Section 3 motivates our empirical approach and discusses estimation methods and data. Section 4 presents the results, and Section 5 concludes.

\section{Institutional Background}

In most countries of the world, a significant share of broadcasting is provided by public broadcasters, which are mostly funded by broadcasting licence fees (Newcomb, 2004). A typical licence fee system is in place in Austria. According to the Austrian Broadcasting Licence Fee Act (BLFA in the following), every household must register its operational TVs and radios. Irrespective of the number of household members, only one licence fee has to be payed per household. Technically, however, public broadcasting programs can also be received without paying the annual fee, which ranged from $€ 206$ to $€ 263$ in $2005 / 2006{ }^{4}$ Licence fees are managed by 'Fee Information Service', henceforth FIS, a subsidiary of the Austrian Public Broadcasting Company. In 2005, 94\% of all Austrian households were registered and payed a total of $€ 650$ million ( $0.3 \%$ of GDP). ${ }^{5}$

The number of registered households is in permanent flux. In principle, households can always de-register, stating that they no longer operate any broadcasting receiver. Those who do so, however, will be thoroughly checked by the FIS enforcement division (see below). An easier way to escape fees emerges in case of moving. Broadcasting registrations are attached to the place of residence, and the law requires moving households to update their registration details with FIS. De-registering at the old place without registering at the new place gives households an opportunity to start evading without the need to explicitly state the absence of TV and radio receivers.

FIS tracks evasion of fees by comparing residence data with its own data base. In principle, all residents who have not registered a TV or radio are treated as potential evaders. Of course, this mechanism does not perfectly identify those who do not comply with

\footnotetext{
${ }^{4}$ License fees are typically paid by direct debit. There also exists a reduced fee which only covers radios $(€ 60-€ 76$ p.a.). All fees differ between the federal states.

${ }^{5}$ Less than one percent of households hold neither a radio nor a TV (Statistics Austria, 2006). The figure of $94 \%$ therefore gives a reasonable proxy for the overall compliance rate.
} 
the BLFA, but it provides FIS with well-defined targets for specific enforcement measures: potential evaders are first addressed in a mailing, which asks them to clarify their status and register for licence fees. ${ }^{6}$ The data of those who do not respond to a mailing are then handed over to FIS' enforcement division. Members of this division, so called "licensing inspectors", enforce the BLFA in the field by personally approaching target households. FIS can impose a fine of up to $€ 2,180$ on detected evaders. In addition, a detected household eventually has to pay evaded fees for several past months. Note that the maximum level of fines is also communicated in the 100,000 mailings which are sent by FIS every year. The availability of this penalty is reflected in a recent national survey, finding that $55 \%$ of Austrian households expect 'severe' or 'very severe' sanctions if they are detected cheating on licence fees. ${ }^{7}$

From November 2005 to March 2006, mailings resulted in 12,327 registrations, while field inspections contributed a total of 28,193 new registrations. However, as shown in Table 1, the bulk of registrations came from unsolicited registrations. Such registrations originate from households who send in a hard-copy registration form which is available at municipal and post offices as well as at branches of banks. Alternatively, one may also register online, using a web form, or by phone. In the five months covered by our data, hard-copy forms accounted for 31,164 unsolicited registrations, while 17,864 households registered online or via phone.

For what follows, it will be useful to highlight several features of FIS' enforcement system. During the period under consideration, 207 inspectors were active, most of them working part-time. As mentioned above, inspectors are non-uniformed and do not use any official, police-like but their private cars. In contrast to police on the streets, the presence of licensing inspectors is therefore not visible to the general public. Each inspector gets assigned a limited number of municipalities (18 on average, with several overlaps). They

\footnotetext{
${ }^{6}$ See Fellner, Sausgruber, and Traxler (2009) for a field experiment testing different strategies in these mailings.

${ }^{7}$ For black labor market participation [skiving off work], the corresponding figure is $60 \%$ [38\%]. The data from this survey $(N=1138)$, which are further discussed in Traxler and Winter (2009), are available from the authors.
} 
Table 1: Number of new registrations by type (Nov 2005 - Mar 2006)

\begin{tabular}{lcc}
\hline Type of registration & Count & Percentage \\
\hline Response to mailing & 12,327 & 13.77 \\
Field inspection & 28,193 & 31.48 \\
Unsolicited registration & 49,028 & 54.75 \\
- hard-copy & 31,164 & 34.80 \\
- online and phone & 17,864 & 19.95 \\
\hline Total number of registrations & 89,548 & 100.00 \\
\hline
\end{tabular}

are payed according to a simple piece-rate contract (without any fixed income component), earning a premium of $€ 20$ for every new registration they deliver. Equipped with information on target households, inspectors independently choose their effort. In particular, they independently decide when and where to become active. Neither are there any public announcements which municipalities are going to be inspected nor is there any coordination among individual inspectors. FIS solely requires inspectors to cover every municipality within their domain at least once per year. However, as travel expenses are not reimbursed, inspectors seem to have little incentives to regularly cover remote and sparsely populated areas.

Inspectors are credited for two types of registrations. First of all, they get the piece-rate for each registration generated by face-to-face interaction with a target household. When it does not come to personal interaction (e.g. nobody was met at home), inspectors leave an information brochure with a registration form. If the form is returned later, FIS identifies the respective inspector from a code printed on the form and credits the inspector with the registration ( $8 \%$ of all registrations credited with field inspectors emerge in this way).

\section{Measuring Deterrence}

Our analysis focuses on the choice to register for licence fees and the impact of enforcement on this decision. Before turning to the estimation approach and the data, we briefly discuss the relation between registering, self-reporting and enforcement. 


\subsection{Registering, Self-Reporting and Enforcement}

Consider the decision of an agent $j$ to register or not to register his TV in a simple one period setting. If he does register, he has to pay licence fees and his utility is $U_{j}^{r}$. If he does not register, he may get detected by a licensing inspector resulting in a utility level of $U_{j}^{d}$. In case he remains undetected, he does not pay fees and his utility is $U_{j}^{u}$, with $U_{j}^{u}>U_{j}^{d}$. The agent will prefer to register whenever

$$
U_{j}^{r} \geq p_{j} U_{j}^{d}+\left(1-p_{j}\right) U_{j}^{u}
$$

where $p_{j}$ denotes the perceived risk of detection. ${ }^{8}$

Our analysis focuses on potential evaders, for which $U_{j}^{u}>U_{j}^{r}>U_{j}^{d}$. For these agents, evading fees is potentially attractive. For a sufficiently high detection risk $p_{j}$, however, condition (1) will be met and the potential evader is deterred: he would register. ${ }^{9}$ Such a registration can be interpreted as an implicit form of self-reporting: whenever these agents register, they do so because they "fear more severe treatment if they do not" (Kaplow and Shavell, 1994, p.583). In our case, they avoid fines, supplementary payments of fees and the embarrassing interaction with a field inspector.

Let us now turn to the link between self-reporting behavior and the enforcement activity of licensing inspectors. We consider the formation of agents' risk perceptions, $p_{j}$, as the process through which enforcement can affect registrations. ${ }^{10}$ Generally, one might think of individuals updating their beliefs about the detection risk based on their own experience

\footnotetext{
${ }^{8}$ The case of heterogenous risk perceptions is supported by many studies which report substantial variation in the perceived risk of detection. E.g., see Lochner (2007), Montmarquette et al. (1985), and Richards and Tittle (1982).

${ }^{9}$ FIS runs intensive campaigns to support registration. For instance, during the time considered in this study, FIS placed about three spots per day in countrywide broadcasted TV and radio channels. We therefore do not consider unintentional evasion as a problem of any practical importance. One could nevertheless consider a different type of agents with $U_{j}^{r} \geq U_{j}^{u}>U_{j}^{d}$, reflecting a preference for registering - irrespective of the risk perception. For these agents, non-compliance can never yield a utility gain, even if it remains undetected. As a consequence, changes in risk perceptions will not trigger any behavioral response.

${ }^{10}$ One could equivalently study the formation of the agents' perceptions of sanctions, reflected in $U_{j}^{d}$. As our data cover information on detections but not on fines, we follow Sah (1991), focussing on the perceived detection risk.
} 
(establishing a direct deterrent effect of enforcement) as well as on information obtained from others (giving rise to an indirect deterrent effect). A formal analysis of the indirect channel is provided by Sah (1991). In his model, agents update their beliefs on the detection risk, making use of information obtained from sampling in their vicinity. An increase in the number of detections within this sample would ceteris paribus result in an increased risk perception. In turn, the propensity to commit a crime decreases.

Hence, learning about detections establishes a positive link between the actual and the perceived detection risk. Given that such a link exists we expect a rise in the number of detections within a municipality to trigger an increase in local self-reporting: the more households are detected by licensing inspectors, the more likely an evader will be confronted with a higher number of detections among his neighbors, friends and acquaintances. As a consequence, the perceived risk of detection rises, and so does the evader's inclination to register. Due to this link between detections and individual perceptions, enforcement has the potential to exert an indirect deterrent effect on individuals who have not been subject to enforcement. It is this spillover that we are going to study in the following.

\subsection{Empirical Approach}

The primary aim of our empirical analysis is to identify the causal effect of enforcement on self-reporting. More precisely, we want to assess to which extent licence fee evaders register their broadcasting receivers in response to an increased number of detections within their municipality.

We employ monthly data on enforcement and unsolicited registrations at the municipality level. Our two key variables are the effective enforcement rate (Enforcement $\left.{ }_{i t}\right)$ and the registration rate $\left(\right.$ Registration $\left._{i t}\right)$. The former measures monthly detections within a municipality - the number of registrations credited with field inspectors - per 1,000 households, whereas the registration rate is the corresponding rate of unsolicited registrations. 
The latter rate is taken to be determined by

$$
\text { Registration }_{i t}=\alpha+\beta \text { Enforcement }_{i t}+\gamma \text { Mobility }_{i t}+\theta_{i}+\eta_{t}+\epsilon_{i t},
$$

where the subscripts $i$ and $t$ denote municipalities and months, respectively. Mobility captures individuals moving into or within the municipality relative to the total number of households, ${ }^{11} \alpha$ is a constant, $\theta_{i}$ and $\eta_{t}$ account for unobserved municipality and periodspecific effects, respectively, and $\epsilon_{i t}$ is a residual. The parameter of interest, $\beta$, measures the impact of enforcement on registrations.

Conceptually, our approach differs from other work on law enforcement as we study the link between enforcement and 'quit decisions' of those who violate the law (the decisions of households who currently evade licence fees and stop doing so) rather than the link with crime. By focusing on quit decisions, we avoid typical problems with the measurement of crime as well as the possibility of crime displacement: if a local increase in enforcement has a positive effect on quit rates, this clearly captures deterrence and cannot be due to the relocation of unlawful activity to other places.

As in many related contributions, the estimation of the model parameters is complicated by the likely endogeneity of the enforcement rate. The problem is akin to the simultaneity problem in studies addressing the impact of police on crime (Corman and Mocan, 2000; Di Tella and Schargrodsky, 2004; Levitt, 1997, 2002). The endogeneity derives from the fact that the level of enforcement is not randomly assigned to communities; it rather depends on the level of compliance. If field inspectors are more likely to be present in communities with lower compliance levels (i.e. lower rates of unsolicited registration), we would expect the covariance between Enforcement ${ }_{i t}$ and the residual $\epsilon_{i t}$ to be negative. As a consequence, the OLS estimate of $\beta$ would be biased downwards. Hence, similar as with estimations of the deterrent impact of police on crime, we need to account for the simultaneity between

\footnotetext{
${ }^{11}$ The reason for including mobility is that moving will generate registrations whenever households deregister at the old and re-register for licence fees at the new place. Recall, however, that FIS asks households to just update their address in case of moving instead of de- and re-registering. If most households comply to this procedure, the effect of mobility on the registration rate should be modest.
} 
enforcement and compliance to obtain consistent parameter estimates.

To cope with the endogeneity of the enforcement rate, we make use of instrumental variables (IVs). Our selection of IVs builds upon the incentives faced by the field inspectors. Recall that inspectors independently decide on their effort level (hours worked per month, the number of target households approached, etc.) as well as on which municipalities within their domain to inspect in a given month. Remember further that licensing inspectors are payed a constant piece rate for each registration they enforce, irrespective of the time and effort spent on driving to target households. Given these incentives, we presume the inspectors' overall effort as well as their choice of target households to be sensitive to the costs of going to different areas.

In search of instrumental variables, we draw on descriptors of local weather and driving conditions. These instruments appear promising for two reasons. Firstly, our data cover the winter 2005/06, a long enduring winter with extraordinary heavy snowfalls. In the south-eastern regions of Austria, for instance, the snowfall during November 2005 alone amounted to more than $70 \%$ of the total snowfall in an average winter season. In December, weather stations in the north and east registered record breaking snow levels - the average amount of fresh snow measured at 241 stations located over all Austria was 73 centimeters (with a median of 59 and a maximum of 235 centimeters). In January (February) 2006, the average depth of snow was $50 \%(37 \%)$ above the long-term average. In March, the corresponding number was $120 \%$. These extraordinary weather conditions are also reflected in the statistics on car accidents: the number of accidents which occurred on snow covered streets was $90 \%$ above the level recorded for the mild winter of 2007.

Secondly, due to its location in the Eastern Alps, Austria is a very mountainous country with substantial variation in altitude: while the lowermost parts of Austria are around 100 meters above sea level, only $32 \%$ of the municipalities are located below 500 meters. $25 \%$ of all municipalities are located at altitudes higher than 675 meters, and $10 \%$ at altitudes above 900 meters. In the lowermost parts of Austria, reasonable driving conditions are typically restored rather quickly, even after heavy snowfalls. In the more mountainous 
areas, however, conditions often remain critical for many days, in particular during periods of persistent snowfall. Driving to more remote, alpine municipalities then requires special equipment like snow chains.

Based on these considerations, we selected three variables as instruments for the enforcement rate: the amount of fresh snow (Snowfall), the interaction with the average altitude of a municipality (Snowfall $\times$ Altitude), and - as an additional measure capturing variation in driving conditions - the frequency of car accidents within the different municipalities (Accidents). While the main effect of altitude is captured by the municipality fixed effects, the interaction of snowfall with the local altitude allows a given level of snowfall to have a different, presumably stronger, impact in more mountainous areas. The first-stage regression then reads

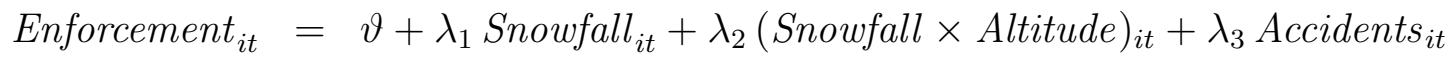

$$
\begin{aligned}
& +\mu \text { Mobility }_{i t}+\psi_{i}+\chi_{t}+\omega_{i t},
\end{aligned}
$$

where $\psi_{i}$ and $\chi_{t}$ denote municipality and period effects, respectively, and $\omega_{i t}$ is the first-stage residual.

\subsection{Data}

Our data set is based upon a record of all licence fee registrations by individual households between November 2005 and March 2006. FIS provided us with comprehensive micro data comprising a total of roughly 90,000 observations. For each individual registration, we observe detailed information on the households' place of residence (complete street address and ZIP code) as well as the type of registration as listed in Table 1. For unsolicited registrations, we know the date of the registration. For enforced registrations, we have information on the month in which the household was detected.

In a first step, we geocoded the micro data by matching geographic coordinates to each individual registration. We then assigned each observation to one of the 2,380 Austrian 
municipalities (larger cities are split into zip code areas) and aggregated the micro data to municipality-month cells, using the five month period starting with November 2005. Effectively, this procedure provided us with a municipality-by-month panel data set with enforcement rates as well as registration rates for the different registration types. All these rates give the number of incidents relative to the number of households within a municipality.

Our main results are based on a sample which essentially cuts the lower tail of the municipality distribution in terms of population size. Firstly, we exclude municipalities with less than 500 households. The main reason for doing so is that these municipalities rarely see any enforcement. As a consequence, our key explanatory variable does not show significant variation in very small municipalities: almost $80 \%$ of the dropped municipalities do not contain a single enforced registration over all five months. Secondly, we exclude municipalities where we could not assign sufficiently precise geographic coordinates to the individual observations. This restriction assures a high accuracy in the assignment of registrations and incidents of enforcement to municipalities as well as in various measures of physical distance between incidents which are introduced below. Thirdly, we eliminate municipalities without any location (bank, postal office, etc.) offering FIS' hard-copy registration forms. This removes municipalities where the lack of hard-copy registration forms could potentially induce correlation between the registration rate and our weather-related instruments, which would question the validity of the exclusion restrictions (see discussion below). Effectively, the three restrictions leave us with 1,275 municipalities observed over five months. ${ }^{12}$

Summary statistics on our key variables and several municipality characteristics are listed in Table 2. On average, we observe 1.13 enforced registrations per 1,000 households. ${ }^{13}$

\footnotetext{
${ }^{12}$ Our parameter estimates are robust to relaxing these sample restrictions. In particular, the estimated effect of enforcement is virtually the same if we include all municipalities. However, using the full sample weakens the IVs in the first-stage regression. A similar finding is reported by Levitt (1997, p. 283-4).

${ }^{13}$ The maximum of the enforcement rate comes from a municipality with 740 households where $13 \%$ of them were detected evading. In the same month, the rate of unsolicited registrations jumped to $1.5 \%-10$ times the municipality's mean registration rate in the four remaining months.
} 
Table 2: Descriptive Statistics

\begin{tabular}{lcccc}
\hline Variable & Mean & Std. Dev. & Min & Max \\
\hline Enforcement rate & 1.13 & 5.10 & 0 & 130 \\
Registration rate, unrestricted & 2.60 & 2.43 & 0 & 46.4 \\
Registration rate, restriction A & 1.80 & 2.13 & 0 & 46.4 \\
Registration rate, restriction A \& B & 1.75 & 2.05 & 0 & 46.4 \\
Registration rate, restriction A \& C 50 & 1.70 & 2.01 & 0 & 46.4 \\
Registration rate, restriction A \& C 75 & 1.68 & 2.00 & 0 & 46.4 \\
Registration rate, restriction A \& C 100 & 1.67 & 1.99 & 0 & 46.4 \\
Registration rate, restriction A \& C 125 & 1.65 & 1.98 & 0 & 46.4 \\
Registration rate, restriction A \& C 150 & 1.64 & 1.97 & 0 & 46.4 \\
Snowfall & 0.42 & 0.34 & 0.01 & 2.60 \\
Accident rate & 0.34 & 0.64 & 0 & 9.46 \\
Mobility rate & 15.5 & 13.4 & 0 & 548 \\
Altitude & 456 & 222 & 117 & 1444 \\
Number of households & 2359 & 7278 & 500 & 115245 \\
Population density & 360 & 1622 & 5.15 & 25629 \\
Municipality size & 39.5 & 38.0 & 1.09 & 285 \\
\hline
\end{tabular}

Number of observations: $6375(N=1275, T=5)$. All rates defined as total number of monthly incidents per 1000 households. Snowfall and Altitude are measured in meters, Municipality size in square kilometers, Population density in inhabitants per square kilometer. Restrictions on the registration rate: Restriction $A$ excludes unsolicited registrations which were made online or by phone. Restriction $B$ excludes unsolicited registrations which from households living in multi-unit dwellings, where in the same month a registration was enforced by a field inspector. Restriction $C_{\ell}$ excludes unsolicited registrations from household living within $\ell$ meters to a place, where in the same month a registration was enforced by a field inspector.

Data sources: FIS (enforcement and registrations); Institute for Meteorology and Geodynamics, Vienna (snowfall); National Council on Traffic Safety (accidents); Austrian Bureau of Statistics (mobility, altitude, number of households, municipality size, population density).

With a mean registration rate of 2.6, unsolicited registrations are more frequent. For a number of refinements to be discussed below we will impose restrictions on this rate. First, we compute a registration rate which excludes all online and phone-call registrations (Restriction A). This restricted rate, which is only based on unsolicited registrations from hard-copy forms, has a mean value of 1.8. Next, we impose additional restrictions based on the geographical proximity of households with unsolicited registrations to evaders who got detected by an inspector: Restriction $B$ eliminates unsolicited registrations which come from multi-unit dwellings (apartment houses, blocks, etc.), where in the same month a registration was enforced by a field inspector. Finally, we compute the minimum distance of each unsolicited registration to the next enforced registration in the same month. Based on this distance measure, we impose Restriction $C_{\ell}$, which omits unsolicited registrations from households living within $\ell$ meters to the next enforcement incidence. Drawing larger 
circles around cases of enforced registrations gradually reduces the restricted registration rate from 1.70 (for $\ell=50)$ to $1.64(\ell=150)$.

Turning to our instruments, we use data from two additional sources. From the Institute for Meteorology and Geodynamics in Vienna we obtained the monthly records of 241 weather stations located over all Austria. To each municipality we assigned the records from the closest weather station (in terms of the great-circle distance between each station and the centroid of the respective municipality). For the snowfall variable, we use the accumulated amount of fresh snow for each month. Together with the municipalities' altitude above sea level, this provides us with our first two instruments, Snowfall and Snowfall $\times$ Altitude. The National Council on Traffic Safety provided us with data on monthly accidents at the municipality level. We use the number of daytime accidents as a descriptor of driving conditions. ${ }^{14}$ The corresponding accident rate (relative to 1,000 households) forms our third instrument.

The measure for mobility is based on data provided by the Austrian Bureau of Statistics. We computed the mobility rate as the number of individuals who moved into or within a municipality relative to the number of households. ${ }^{15}$ Finally, note that our sample covers municipalities from an altitude of 117 to more than 1400 meters, with an average number of 2359 households (median: 905), an average size of about 40 square kilometers and a mean population density of 360 inhabitants per square kilometer (median: 96).

\section{Results}

This section describes our empirical findings. We show that enforcement has a sizable impact on unsolicited registrations, and we demonstrate that the effect is not driven by personal observation or experience. Hence, our analysis suggests that the indirect deterrence

\footnotetext{
${ }^{14}$ Driving under the influence is the main cause for nighttime accidents. We focus on daytime accidents to avoid variation in the instrument that is driven by this type of accidents.

${ }^{15}$ The mobility rate attains unusual high values in some small communities in Austria's main tourist areas, where seasonal workers are officially registered as new residents. Excluding these or any other outliers does not change our results.
} 
Table 3: First-stage regression

\begin{tabular}{lc}
\hline Dependent variable: Enforcement rate & \\
\hline Snowfall & $3.761^{\star \star \star}$ \\
& $(1.044)$ \\
Snowfall $\times$ Altitude & $-0.711^{\star \star \star}$ \\
& $(0.213)$ \\
Accidents & -0.135 \\
& $(0.089)$ \\
\hline Sample size $(N \times T)$ & 6375 \\
$F$-statistic for excluded IVs & 9.60 \\
\hline
\end{tabular}

Standard errors (robust to heteroscedasticity and clustering on municipalities) in parentheses. $F$-statistic valid for i.i.d. errors. Additional regressors: Mobility rate and a full series of period as well as municipality effects. Snowfall is measured in meters and altitude in 100 meters. Significance level: ${ }^{\star \star \star} 1 \%$.

effect of enforcement is based on word of mouth. Finally, we provide evidence that the spillover is limited to the close vicinity of detected households. This points to the role of neighborhood communication in the dispersion of information on the actual enforcement level.

\section{First-Stage Regression}

Before turning to the main results, let us briefly discuss the performance of the IVs in the first-stage regression. Table 3 reports the fixed-effects regression of the enforcement rate on the instruments, i.e. snowfall, snowfall interacted with altitude, and the accident rate, as well as the mobility rate and a full series of period effects. We find that the snowfall-related instruments are strongly partially correlated with the enforcement rate. Interestingly, the coefficient of snowfall is positive whereas the one for the interaction is negative. The firststage coefficients imply that snowfall raises the enforcement rate in municipalities with an altitude below 530 meters, but lowers enforcement in municipalities located higher. The accident rate as a direct measure of driving conditions shows the expected negative sign and is almost significant at the $10 \%$ level: for given weather conditions, inspectors are less active in municipalities where the accident rate is high.

Taken together, the results of the first-stage regression indicate that the behavior of the licensing inspectors is significantly affected by local weather and driving conditions. More 
precisely, the coefficients of the first-stage regression suggest that the activity of inspectors is driven by a sort of substitution effect: they seem to avoid driving to more mountainous areas in periods of heavy snowfall. Instead of reducing their overall effort, however, they just shift their focus and enforce more registrations in more easily accessible municipalities. ${ }^{16}$

Note also that the $F$-statistic of 9.6 indicates that our IVs have substantial predictive power in the first-stage regression, making us confident that we have identified instrumental variables which are sufficiently strongly correlated with the enforcement rate to solve our identification problem. ${ }^{17}$

With respect to the validity of the instruments, one might be concerned about a direct impact of local weather conditions on households' registration behavior. Note, however, that we excluded municipalities without locations offering FIS' hard-copy forms from our analysis, since an impact of weather conditions on registrations (if it is present) appears most likely to occur in such municipalities. Note further that online and phone - in contrast to hard-copy registrations - registrations should (if anything) be positively affected by harsh weather conditions. One might therefore conjecture that our IVs have a negative impact on the share of hard-copy to all unsolicited registrations. To test this conjecture, we regressed the share of hard-copy registrations on our instruments. The results (presented in the Appendix) indicate that all our IVs are far from being statistically significant predictors of the ratio of hard-copy registrations. Further evidence on the validity of the exclusion restrictions (also reported in the Appendix) is based on the fact that a substantial share of all municipalities do not see any enforcement. In this sample, enforcement cannot have any explanatory power, and we can run a reduced form regression that tests for a direct impact of the IVs on registration behavior. Again, our IVs pass the test without any difficulty, making us confident that we have identified a set of valid instruments.

\footnotetext{
${ }^{16}$ This finding seems to be in line with the notion of income targeting (compare the discussion in Camerer et al., 1997, and Farber, 2008).

${ }^{17}$ Using a Stock-Yogo test on weak instruments (Stock and Yogo, 2005), we can reject the null of the 2SLS bias exceeding $10 \%$ of the OLS bias. We also replicated all our estimations using limited-information maximum likelihood (LIML) and its modification by Fuller (1977) (compare Andrews and Stock, 2005, Hahn et al., 2004). All these alternative estimators provided point estimators as well as standard errors which are almost identical to those reported below.
} 


\section{Effect of Enforcement}

Table 4 reports our main estimation results on the effect of enforcement. Column (I) displays the fixed effects OLS estimation of Equation (2), ignoring the likely endogeneity of enforcement. The coefficient of the enforcement rate is estimated to be 0.134 , and it is highly significant. Moreover, we find a positive impact of mobility on registrations, but the effect is far from being economically significant. ${ }^{18}$

As outlined above, we expect the OLS estimate of $\beta$ to be biased downwards. This expectation is confirmed if we turn to the fixed effects IV estimations. Columns (II) to (IV) report results derived from estimating Equation (2) by two-stage least squares (2SLS) while instrumenting enforcement by snowfall, snowfall $\times$ altitude and the accident rate. In Column (II), we retain the unrestricted registration rate as the dependent variable. The effect of enforcement is now estimated to be 0.361, suggesting that the bias in the OLS estimate is substantial. The effect for household mobility is not significantly different from zero. $^{19}$

The coefficient of the enforcement rate indicates a remarkably strong effect. According to the estimates in Column (II), one additional detection leads to about 0.36 additional unsolicited registrations. Hence, on average three additional detections trigger more than one additional registration. Taking into account that the scope for any deterrence effect of detections is limited by the high compliance rate - nationwide only $6 \%$ of all households are evading licence fees - the estimated effect is sizable. To illustrate this point, consider a municipality with 1000 households and an initial enforcement rate of zero. On average, there will be 60 households who have not registered for licence fees. If now a field inspector enforces 20 registrations, we predict another seven unsolicited registrations (assuming a linear effect). In this case, the indirect effect of enforcement would deter $17.5 \%$ of the

\footnotetext{
${ }^{18}$ This is in line with our conjecture that most moving households just update the address in their FIS account instead of de-registering at the old and re-registering at the new place of residence.

${ }^{19}$ Throughout the paper, we focus on the contemporary effect of enforcement. OLS estimations incorporating lagged values of enforcement indicate that this approach is justified: magnitude and significance of the impact of present enforcement are hardly effected, whereas the lagged enforcement rate is neither economically nor statistically significant.
} 


(I) (II) (III) (IV)

\begin{tabular}{lcccc} 
Estimator & FE OLS & FE IV & FE IV & FE IV \\
\hline $\begin{array}{l}\text { Dependent variable } \\
\text { Registration rate }\end{array}$ & unrestricted & unrestricted & restriction A & restriction A \& B \\
\hline Enforcement rate & $0.134^{\star \star \star}$ & $0.361^{\star \star \star}$ & $0.321^{\star \star \star}$ & $0.273^{\star \star \star}$ \\
Mobility rate & $(0.015)$ & $(0.114)$ & $(0.104)$ & $(0.094)$ \\
& $0.007^{\star \star \star}$ & 0.003 & 0.003 & 0.004 \\
& $(0.002)$ & $(0.003)$ & $(0.003)$ & $(0.003)$ \\
\hline Sample size $(N \times T)$ & 6375 & 6375 & 6375 & 6375 \\
Hansen test $(p$-value $)$ & - & 0.287 & 0.200 & 0.222 \\
\hline
\end{tabular}

Standard errors (robust to heteroscedasticity and clustering on municipalities) in parentheses. All estimations include a full series of period effects. Significance levels: $\star \star \star ~ 1 \%$.

Restrictions on the registration rate: Restriction $A$ excludes unsolicited registrations which were made online or by phone. Restriction $B$ excludes unsolicited registrations which were made by a household living in multi-unit dwellings, where in the same month at least one registration was enforced by a field inspector.

remaining evaders.

Regarding the figures from table 1, our estimates suggest that the roughly 30,000 enforced registrations triggered about 10,000 unsolicited registrations (assuming again a linear relationship). Thus, $20 \%$ of all unsolicited registrations emerge as a direct response to local field inspections.

\section{Own Experience or Word of Mouth}

We argue that the impact of enforcement is driven by the local dispersion of information, establishing a positive link between the actual and the perceived detection risk: evaders learn about more frequent detections in their municipality, update their risk perception and are ceteris paribus more inclined to register. In this vain, enforcement triggers a deterrence spillover driven by word of mouth.

The updating of risk perceptions may be based on own experiences and observations as well as on information obtained from neighbors, friends or acquaintances. Regarding the design of optimal enforcement policies, however, it is important to discriminate between both channels. In particular, it is crucial to identify the power of information spread by word of mouth. If communication among acquaintances is sufficient to establish a 
positive detection-perception link, even non-public enforcement activities (e.g. the auditing of potential tax evaders) would result in a deterrence spillover. Otherwise, deterrence relies on the public visibility of enforcement measures. ${ }^{20}$

Despite the fact that the presence of inspectors is not observable to the public, one can think of several ways in which personal experience could drive the deterrent effect of enforcement. For instance, consider people who were absent while a field inspector was at their door. Recall that in these cases inspectors leave an information brochure together with a registration form at the door. Registrations which are made using these forms are identified in our data as enforced registrations. Thus, they do not spoil the count of unsolicited registrations. However, households could (i) ignore the registration form which was left at their door, go to one of the municipal or post offices to pick up another registration form (which looks exactly like the form distributed with inspectors' information brochures) and register with this form. Alternatively, they could (ii) register via phone or internet. We consider the first case as extremely unlikely to happen. In contrast, the second case, i.e. phone or online registration after being approached by an inspector, seems to be quite realistic. Fortunately, our data allow us to identify this type of registrations. Hence, we can compute the rate of unsolicited registrations excluding those which were made by phone or online (Restriction $A$ ) and check the robustness of our findings.

Another scenario where own experience could contribute to the deterrent effect of enforcement is the immediate observation of door-to-door inspections by neighbors. If bystanders who evade fees respond to their observation with a registration, this would still reflect a deterrence spillover from enforcement, but it would be driven by personal experience. $^{21}$ Again our data allow us to run a robustness check testing to which extent such cases might potentially drive our finding. We can do so by excluding all unsolicited reg-

\footnotetext{
${ }^{20}$ We consider it as obvious that public visibility strengthens deterrence (not taking into account effects from stigmatization). In a wide range of applications, however, establishing a clear public observability of sanctions can be quite costly to implement (think of tax enforcement, for instance) and even undesirable from a normative viewpoint (e.g. to avoid undesirable stigmatization in case of false charges, 'lynch law', etc.).

${ }^{21}$ Note that such cases can only emerge if the fact that the bystander evades licence fees is unknown to the field inspector. Otherwise the inspector would directly approach the bystander to enforce a registration.
} 
istrations from households living in apartment buildings or multi-family houses where the data indicate the presence of a licensing inspector in the same month (Restriction $B$ ).

Results based on the restricted registration rates are reported in Columns (III) and (IV) of Table 4. As with the unrestricted registration rate, we find significant effects of enforcement. Despite the fact that restriction A excludes roughly $40 \%$ of all unsolicited registrations and reduces the registration rate from 2.6 to 1.8 (see Table 2), the estimated coefficients for enforcement in Column (III) is only slightly below the one from (II). As shown in Column (IV), the coefficient further decreases if we impose restrictions A and B at the same time. This could mean that some registrations in the neighborhood are indeed driven by personal experience. However, the smaller point estimates could also arise from our restrictions excluding truly unsolicited registrations which are induced by communication among immediate neighbors. In either case: enforcement still has a sizable spillover on registrations, even if we exclude those cases which could be driven by personal experience. Hence, our data suggest that the deterrence spillover is due to word of mouth, mediating the dispersion of information on enforcement and thereby stimulating registrations.

\section{Spatial Limits of the Spillover}

The findings reported so far demonstrate a significant indirect deterrence effect of enforcement. We now want to trace the spatial limits of this effect, i.e. we want to study how far-reaching the behavioral impact of word of mouth is. This is important for assessing whether widely (spatially) spread enforcement activities trigger a larger deterrence spillover than locally focused measures.

Our approach takes advantage of the detailed micro structure of the data base. Exploiting the fact that we observe the exact location of all households with enforced or unsolicited registrations, we computed the distance of each household with an unsolicited registration to the most nearby household who was detected by a field inspector in the same month. Across all individual observations, we find a median distance of 269 meters (mean: 593 meters). $75 \%$ [25\%] of all unsolicited registrations emerge more than 74 meters [680 meters] 
Table 5: Fixed effects IV estimations under spatial restrictions

(I)

\section{Dependent variable}

Registration rate under restriction:

\begin{tabular}{lccccc}
\hline $\begin{array}{l}\text { Minimum distance to } \\
\text { enforcement incident: }\end{array}$ & $50 \mathrm{~m}$ & $75 \mathrm{~m}$ & $100 \mathrm{~m}$ & $125 \mathrm{~m}$ & $150 \mathrm{~m}$ \\
\hline Enforcement rate & $0.207^{\star \star}$ & $0.186^{\star \star}$ & $0.154^{\star}$ & $0.153^{\star}$ & 0.130 \\
& $(0.092)$ & $(0.092)$ & $(0.091)$ & $(0.092)$ & $(0.092)$ \\
Mobility rate & 0.0047 & $0.0054^{\star}$ & $0.0050^{\star}$ & 0.0044 & 0.0025 \\
& $(0.0029)$ & $(0.0029)$ & $(0.0028)$ & $(0.0028)$ & $(0.0027)$ \\
\hline Sample size $(N \times T)$ & 6375 & 6375 & 6375 & 6375 & 6375 \\
Hansen test $(p$-value $)$ & 0.307 & 0.364 & 0.342 & 0.414 & 0.405 \\
\hline
\end{tabular}

Standard errors (robust to heteroscedasticity and clustering on municipalities) in parentheses. All estimations include a full series of period effects. Significance levels: $\star \star \star ~ 1 \%, \star \star 5 \%,{ }^{\star} 10 \%$.

Restrictions on the registration rate: Restriction $A$ excludes unsolicited registrations which were made online or by phone. Restriction $C_{\ell}$ ' excludes unsolicited registrations from households who live within $\ell \in\{50,75, \ldots, 150\}$ meters to a place with an enforced registration in the same month.

away from the next incidence of enforcement.

Based on the distance measure, one can impose another set of restrictions on our dependent variable. For each municipality, we compute the rate of unsolicited registrations excluding those emerging within 50, 75, 100 meters, etc. to the next enforced registration. Maintaining our focus on indirect deterrence, we also adhere to restriction A, which excludes all phone and online registrations. Tightening the spatial restriction, i.e. drawing larger circles around detected households, excludes more unsolicited registrations and yields lower registration rates. As Table 2 reveals, the resulting decline in the rate is quite small. The results displayed in Table 5 show that the spatial restrictions nevertheless have a strong impact on our estimates.

Column (I) reports the fixed effects IV estimation of Equation (2), where the dependent variable is restricted to unsolicited registrations with a minimum distance of at least 50 meter to the next enforced registration. We still find a sizable effect of enforcement, statistically significant at the $5 \%$ level. On average, five detections would trigger one additional unsolicited ('hard-copy') registration beyond the 50 meter circle around enforcement incidences. As compared to the point estimate from Column (III) in Table 4, the coefficient 
is reduced by one third. If we increase the spatial constraint to 75 meters, the effect of enforcement declines further but remains significant at the $5 \%$ level. In Column (III), with a distance threshold of at least 100 meters, the significance level drops to 10\%. Finally, Column (V) shows that for a minimum distance of 150 meters, enforcement is no longer statistically significant at conventional levels. Further tightening the restriction beyond 150 meters does not change the pattern indicated in Table 5: the point estimates for the coefficient continue to decline steadily, while the standard errors remain roughly constant.

The findings reported in Table 5 suggest that the indirect deterrence effect of enforcement is limited to the close vicinity of households who have been subject to enforcement. This supports the interpretation that the spillover effect is mainly driven by word of mouth on enforcement within neighborhoods. However, caution is warranted when interpreting this result, as our data do not allow to identify the role of alternative layers of social interaction. Communication at the workplace, for instance, could contribute to a spillover which may work beyond neighborhoods and even municipalities. Notwithstanding, the results in Table 5 suggest that in our setting, communication within neighborhoods is an important channel that mediates information on detections and thereby shapes the deterrent effect of enforcement. $^{22}$

\section{Concluding Discussion}

This paper studies the role of word of mouth for deterrence. Using data on TV licence fee registrations, we ask whether households who have not been subject to enforcement by licensing inspectors react to changes in the local level of enforcement. Since the actual level of enforcement is likely to be endogenous to registration behavior, our estimations rely on

\footnotetext{
${ }^{22}$ The fact that the deterrence spillover is concentrated in the close neighborhood of detection incidences could - in principle - also stem from the segregation of households into evader and non-evader neighborhoods. Our data render this explanation implausible, since detected households are broadly spread within municipalities. Across all municipalities, the median distance between detected households within a municipality is more than 1300 meters. Compared to the median minimum distance of unsolicited to enforced registrations of 269 meters, this is quite a large distance. In addition, the mere fact that a spatial exclusion with a radius of $\ell=200$ meters reduces the respective registration rate by only $10 \%$ (compare Table 2 ) contradicts this interpretation.
} 
instrumental variables capturing variation in local weather and driving conditions.

We derive three main results. Firstly, we find a strong deterrent effect of enforcement. If enforcement is increased such that three unregistered households are forced to register, this will, on average, induce the registration of one additional household which has not been subject to enforcement. Hence, we show that an increase in enforcement has a significant effect on compliance behavior. Our study therefore corroborates the existing evidence on the deterrent impact of police. This is an important result in its own right since, due to the specific features of our setting, we can exclude the presence of crime displacement effects or erroneous measurement of crime rates.

Secondly, we demonstrate that the deterrent effect works through word of mouth. Distinguishing between households which have been subject to enforcement and those which have not, we are able to show a change in registration behavior of households for which word of mouth on the actual level of enforcement is the only plausible source of new information. Our findings suggest that the key mechanism analyzed by Sah (1991), i.e. the updating of risk perceptions by sampling among acquaintances, can give rise to a strong indirect deterrent effect of enforcement.

Finally we provide evidence pointing to an important role of neighborhood communication for the dispersion of information on enforcement. This relates our findings to studies demonstrating the importance of neighborhood communication for decision making in many different contexts as, for instance, investment decisions (Hong et al., 2005 ) and job search (Ioannides and Loury, 2004).

Having identified the deterrent power of word of mouth, it is self-evident that personal experiences contributes to deterrence, too. This is also confirmed by Lochner (2007), who documents the link between personal experience and individuals' beliefs about arrest probabilities. While in his study beliefs are also correlated with county-level arrest rates, this link is weak - eventually due to the high level of aggregation. In this vein, our municipality-level evidence complements Lochner's findings.

Our study carries a number of implications for the design of optimal enforcement poli- 
cies. When communication among individuals is sufficient to establish a positive link between actual enforcement and the perceived risk of detection, even 'hidden' enforcement activities can have significant deterrence spillovers. Furthermore, the sizable indirect deterrent effect found in our data illustrates that it is crucial to consider indirect deterrence effects when assessing the marginal social benefits from enforcement activities. For law enforcement in a domain where public visibility is costly to implement, it might be efficient to stick to hidden enforcement measures. This applies particularly to cases where there are either normative (e.g. avoiding undesirable stigmatization in case of false charges) or strategic reasons to prevent publicity.

Several points are left for future research. In particular, we would like to know more about the long-run role of word of mouth on enforcement in altering risk perceptions and behavior. While our results focus on the short-run linkage, a better understanding of the long-term formation of perceptions might be useful to improve the effectiveness of enforcement. Due to the short time spell covered by our data, a proper analysis of this issue is beyond the scope of the present study. The same holds true for the potential heterogeneity of deterrence through word of mouth. It would be interesting to explore how the transmission of information on enforcement depends on municipality or neighborhood characteristics. The identification of this heterogeneity, however, is complicated by additional layers of cross-sectional variation (in terms of risk aversion, the level of non-compliance, etc.), which all interact in shaping the actual deterrent effect of enforcement. Further empirical research on the link between enforcement and the formation of individual perceptions is needed to clarify this and several other related questions. 


\section{References}

Andrews, D. W., And J. H. Stock (2005): "Inference with Weak Instruments," NBER Technical Working Paper 0313.

Becker, G. S. (1968): "Crime and Punishment: An Economic Approach," Journal of Political Economy, 76(2), 169-217.

Camerer, C., L. Babcock, G. Loewenstein, and R. Thaler (1997): "Labor Supply of New York City Cabdrivers: One Day at a Time," Quarterly Journal of Economics, $112(2), 407-441$.

Corman, H., and H. N. Mocan (2000): "A Time-Series Analysis of Crime, Deterrence, and Drug Abuse in New York City," American Economic Review, 90(3), 584-604.

Di Tella, R., and E. Schargrodsky (2004): "Do Police Reduce Crime? Estimates Using the Allocation of Police Forces After a Terrorist Attack," American Economic Review, 94(1), 115133.

Drago, F., R. Galbiati, and P. Vertova (2007): "The Deterrent Effects of Prison: Evidence from a Natural Experiment," IZA Discussion Papers No. 2912.

Farber, H. S. (2008): "Reference-Dependent Preferences and Labor Supply: The Case of New York City Taxi Drivers," American Economic Review, 98(3), 1069-82.

Fellner, G., R. Sausgruber, and C. Traxler (2009): "Legal Threat, Moral Appeal and Social Information: Testing Enforcement Strategies in the Field," Mimeo, Max Planck Institute for Research on Collective Goods, Bonn.

Fuller, W. A. (1977): "Some Properties of a Modification of the Limited Information Maximum Likelihood Estimator," Econometrica, 45(4), 939-954.

Hahn, J., J. Hausmann, and G. Kuersteiner (2004): "Estimation with Weak Instru- 
ments: Accuracy of Higher Order Bias and MSE Approximation," Econometrics Journal, $7(1), 272-306$.

Hong, H., J. D. Kubik, And J. C. Stein (2005): "Thy Neighbor's Portfolio: Wordof-Mouth Effects in the Holdings and Trade of Money Managers," Journal of Finance, 60(6), 2801-24.

Horney, J., And I. H. Marshall (1992): "Risk Perceptions among Serious Offenders: The Role of Crime and Punishment," Criminology, 30(4), 575-594.

IoAnnides, Y. M., AND L. D. LouRY (2004): "Job Information Networks, Neighborhood Effects, and Inequality," Journal of Economic Literature, 42(4), 1056-1093.

Jacob, B., L. Lefgren, And E. Moretti (2007): "The Dynamics of Criminal Behavior: Evidence from Weather Shocks," Journal of Human Resources, 42(3), 489-527.

Kaplow, L., and S. Shavell (1994): "Optimal Law Enforcement with Self-Reporting of Behavior," Journal of Political Economy, 102(3), 583-606.

Kessler, D., and S. D. Levitt (1999): "Using Sentence Enhancements to Distinguish between Deterrence and Incapacitation," Journal of Law and Economics, 42(1), 343-63.

LevitT, S. D. (1997): "Using Electoral Cycles in Police Hiring to Estimate the Effect of Police on Crime," American Economic Review, 87(3), 270-90.

(1998): "Why Do Increased Arrest Rates Appear to Reduce Crime: Deterrence, Incapacitation, or Measurement Error?," Economic Inquiry, 36(3), 353-72.

_ (2002): "Using Electoral Cycles in Police Hiring to Estimate the Effects of Police on Crime: Reply," American Economic Review, 92(4), 1244-1250.

Lochner, L. (2007): "Individual Perceptions of the Criminal Justice System," American Economic Review, 97(1), 444-460. 
MacDonald, Z. (2002): "Official Crime Statistics: Their Use and Interpretation," Economic Journal, 112, F85-F106.

Miguel, E., S. Satyanath, and E. Sergenti (2004): "Economic Shocks and Civil Conflict: An Instrumental Variables Approach," Journal of Political Economy, 112(4), $725-753$.

Montmarquette, C., M. Nerlove, and P. Forest (1985): "Deterrence and Delinquency: An Analysis of Individual Data," Journal of Quantitative Criminology, 1, 37-58.

NaGin, D. S. (1998): "Criminal Deterrence Research at the Outset of the Twenty-First Century," Crime and Justice, 23, 1-42.

Newcomb, H. (ed.) (2004): The Museum of Broadcast Communications Encyclopedia of Television. Routledge, New York, 2nd edn.

Parker, J., And H. G. Grasmick (1979): "Linking Actual and Perceived Certainty of Punishment: An Exploratory Study of an Untested Proposition in Deterrence Theory," Criminology, 17(3), 366-379.

Paternoster, R., L. E. Saltzman, G. P. Waldo, and T. G. Chiricos (1985): "Assessments of Risk and Behavioral Experience: An Exploratory Study of Change," Criminology, 23(3), 417-436.

Piliavin, I., R. Gartner, C. Thornton, and R. L. Matsueda (1986): "Crime, Deterrence, and Rational Choice," American Sociological Review, 51(1), 101-119.

Richards, P., And C. R. Tittle (1982): "Socioeconomic Status and Perceptions of Personal Arrest Probabilities," Criminology, 20(3-4), 329-346.

SAH, R. K. (1991): "Social Osmosis and Patterns of Crime," Journal of Political Economy, 99(6), 1272-95. 
Statistics Austria (2006): "Ergebnisse der Europaeischen Erhebung ueber den Einsatz von Informations- und Kommunikationstechnologien in Unternehmen und Haushalten 2006," Statistics Austria, Vienna.

Stock, J. H., and M. Yogo (2005): "Testing for Weak Instruments in Linear IV Regression," in Identification and Inference for Econometric Models: Essays in Honor of Thomas Rothenberg, ed. by D. W. Andrews, and J. H. Stock, pp. 80-108. Cambridge University Press, Cambridge.

Traxler, C., And J. Winter (2009): "Survey Evidence on Conditional Norm Enforcement," Working Paper 2009-03, Max Planck Institute for Research on Collective Goods, Bonn. 


\section{Appendix: Validity of Instruments}

A potential concern regarding our IV strategy is that unsolicited registrations, in particular those made by hard-copy forms, could be directly influenced by the local weather conditions. This would be the case if the willingness to go to one of the locations that provide the necessary registration form is affected by snowfall. The forms are available at almost 6,400 municipal and post offices as well as at branches of banks. On average, there are 4.5 such locations per 1,000 households. Moreover, these locations are typically located at central places within a community and in shopping areas. In general, it is hard to think of people who are - for an entire month - detained from passing these areas due to weather conditions.

Let us nevertheless address the concern in more detail. Note first that we have excluded municipalities which do not have any location offering FIS forms from our sample of municipalities, because in such municipalities a dependence of hard-copy registrations on snowfall is most likely. A straightforward approach to test the validity of our IVs is to check for a potential impact of our descriptors of local weather conditions on registration behavior by means of regressions. Obviously, harsh weather conditions could decrease the willingness of households to register via hard-copy forms, as this implies some sort of outdoor mobility, suggesting that the share of hard-copy registrations among all unsolicited registrations should go down (and, vice versa, the share of online and phone registrations should go up) in months with heavy snowfalls. ${ }^{23}$

We test this hypothesis by regressing the share of hard-copy registrations on our instruments. The results (see Table 6) indicate that snowfall is far from being a statistically significant predictor of the share of hard-copy registrations, lending further support to the view that our identification relies on a set of valid instruments.

A second test exploits the fact that a substantial share of all municipalities do not see any enforcement over all five months considered. If we restrict our attention to the sample

\footnotetext{
${ }^{23}$ Telecommunication networks in Austria are designed to remain unaffected even by severe winter conditions. Hence, there is no reason to think that online and phone registrations will be negatively affected by snowfall.
} 
Table 6: Fixed Effects Estimation - Share of hard-copy form registrations

\begin{tabular}{|c|c|c|c|c|c|}
\hline & (I) & (II) & (III) & $(\mathrm{IV})$ & $(\mathrm{V})$ \\
\hline Snowfall & $\begin{array}{l}-0.024 \\
(0.025)\end{array}$ & $\begin{array}{c}-0.001 \\
(0.062)\end{array}$ & $\begin{array}{c}-0.024 \\
(0.025)\end{array}$ & - & $\begin{array}{c}-0.001 \\
(0.062)\end{array}$ \\
\hline Snowfall $\times$ Altitude & - & $\begin{array}{c}-0.004 \\
(0.010)\end{array}$ & - & - & $\begin{array}{c}-0.004 \\
(0.010)\end{array}$ \\
\hline Accidents & - & - & $\begin{array}{c}-0.004 \\
(0.008)\end{array}$ & $\begin{array}{c}-0.004 \\
(0.008)\end{array}$ & $\begin{array}{r}-0.004 \\
(0.008)\end{array}$ \\
\hline Sample size & 5412 & 5412 & 5412 & 5412 & 5412 \\
\hline
\end{tabular}

of these municipalities, enforcement cannot have any explanatory power. With no need to account for enforcement and, thus, to impose an exclusion restriction with respect to the IVs, we can estimate a reduced form,

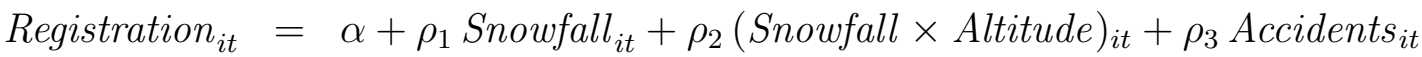

$$
\begin{aligned}
& +\gamma \text { Mobility }_{i t}+\theta_{i}+\eta_{t}+\epsilon_{i t} \text {. }
\end{aligned}
$$

In this regression, we just have to evaluate the $t$-statistics of $\rho_{1}, \rho_{2}$ and $\rho_{3}$ to test for a direct impact of our IVs on registration behavior. Table 7 reports two different reduced form regressions. Column (I) uses the unrestricted registration rate as the dependent variable and derives the direct effect of the IVs on registrations. The estimation is based on a balanced panel of municipalities with zero enforcement over the whole period considered (note that this is a subsample of those communities which were used to derive our main results). It turns out that for all IVs, i.e. Snowfall, Snowfall $\times$ Altitude, and Accidents, the null of no impact on the registration rate cannot be rejected at any reasonable level of significance. Since a potential effect of weather and driving conditions on registrations is most likely for hard copy registrations, we report in Column (II) the reduced form regression using the registration rate under Restriction A (phone and online registrations excluded). The results closely match those obtained in the first Column. Moreover, the IVs remain insignificant also if we regress the registration rate one each instrument separately (results not reported). 
Table 7: Reduced-form estimation for municipalities with zero enforcement

(I)

(II)

\begin{tabular}{lcc}
\hline Dependent variable: & unrestricted & Restriction A \\
Registration rate & 0.159 & 0.224 \\
Snowfall & $(0.628)$ & $(0.661)$ \\
& -0.068 & -0.062 \\
Snowfall $\times$ Altitude & $(0.108)$ & $(0.112)$ \\
& -0.035 & -0.042 \\
Accidents & $(0.046)$ & $(0.054)$ \\
Mobility rate & 0.003 & 0.002 \\
& $(0.005)$ & $(0.005)$ \\
\hline Sample size & 2690 & 2690 \\
\hline
\end{tabular}

Fixed effects estimation including a full series of period effects. Sample consists of balanced panel of municipalities with zero enforcement over all five months. Standard errors (robust to heteroscedasticity and clustering on municipalities) in parentheses.

Hence, estimations of the reduced form for the subsample of municipalities with zero overall enforcement provide strong support for the validity of the exclusion restriction on our IVs. 